\section{Cutting Keyways in a Lathe}

By William H. Trueman, D.D.S.

$T^{\text {HE }}$ following method of key-seating by using I a lathe as a planer has been found very satisfactory, and with slight modifications, equally satisfactory for cutting slots. A block of wood $A$ say 6 by 12 inches, and about one inch thick, with a groove $B$ to hold the shaft, and a hole $T$ fo tool post, is fitted over the tool post of the slide rest and held firmly by a tool passing through the slot in the post and screwed down upon the block. Two piece of wood $C$, at each side of the tool post, supported by blocks $D$ at one end, the other resting on the shaft, ar fastened by bolts $E$ passing through holes $F$ to clamp the shafts in place. The block is bolstered up so as to bring the center of the shaft opposite the lathe center.

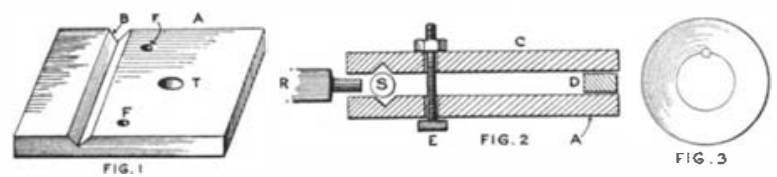

Cutting a key in a lathe.

These adjustments accurately made, a drill of suitable size is used to make a series of holes close together, and in a row as long as the key-seat is intended to be, and nearly as deep. This done, the drill is replaced by nearly as deep. This done, the drill is replaced by
an end-cutting reamer $R$. Using the lathe as a milling an end-cutting reamer $R$. Using the lathe as a milling
machine, the key-seat may be neatly and quickly finmachine, the key-seat may be neatly and quickly finished. For key-seating the pulley, fit into the bore the reamer used on the shaft, drill a hole at the juncthe of the plug and the pulley hub, half of its diamete in each, and finish with a file. To ker-seat a pulley in each, and finish with a file, To key-seat a at the end of a shaft, simply drill a hole of suitable size at the junction of the shaft and the bore the full length of the hub, and drive into it a tight-fittin round rod. There is an advantage in locating the key seat directly under the set-screw of the pulley, as by cutting a groove across the key the set-screw will hold the pulley in position lengthwise of the shaft These sugrestions are not original, they are old to many, but may be new to some.

\section{Construction of a Water-tight Box} By W. A. L. $\Gamma_{\text {way requires a great deal of care with the joints, but }}^{O}$ the following method does not call for much skill. Select any soft material for its swelling qualities and to stand close nailing. Fix the bottom piece first by dressing both edges straight and square. Then make a rage blok as shown. The gage block $A$ is 4 inches wide $B$ is 2 inches wide and both are 6 inches long, made of 1-inch stuff. Fasten the block $B$ on one long, made of 1-inch stuff. Fasten the block $B$ on one
edge of block $A$, with a few light nails, and in the edge of block $A$, with a few light nails, and in the center of one end of block $A$ fasten a 20 -penny spike as at $C$, with small staples or with small nails driven in half way and bent over the spike to hold it in place. Have the spike project about half its length and drive the head into the wood. Now apply the gage block, as shown in the drawing, to the edge of bottom piece $E$. The spike $C$ that projects should lie at about the center of the edge. Now starting at one end of the bottom piece, hammer the spike $C$ to form a semi-circular groove $D$. In soft wood it only takes a medium, sure tap of the hammer to make the spike form this groove. Then move the block about 2 inches and strike again, and so ton wicking in the grooves with tacks. Now prepare the sides and ends. It is best first to bore holes through the sides along the edge that nails to the bottom. Use the sides along the edge that nails to the bottom. Use
a bit about the size of the nails, staggering the holes a bit about the size of the nails, staggering the holes
and boring them about 4 inches apart. Nail the sides and boring them about 4 inches apart. Nail the sides
and ends on and the box is ready to fill with water to swell it; when the water swells the compressed wood around the groove and the cotton wicking, it will make a water-tight joint. This kind of a joint will hold water as well as any made with a combination plane.

\section{A Variable Speed Groove-pulley} By F. E. Keller VARIABLe speed groove-pulley which will con-
vey light power may be made as follows: Turn out a hub as shown in Fig. 1. Then make a cone of heavy sheet iron, laying it out as indicated in Fig. 2 Cut slots in the sheet from the periphery inward, wid enough to receive the wire spokes shown in Fig. 5, placing them as close together as possible and being careful to have the metal strong enough in the center. Then bend the sheet around into a cone with edges $a$ and $b$ together and rivet it to the flange of the hub, as shown in Fig. 3. Next turn out another hub and fit as many threaded spokes into it as there are slots in the cone, setting them at such an angle as to form a conical row of the same angle as the sheet iron cone.

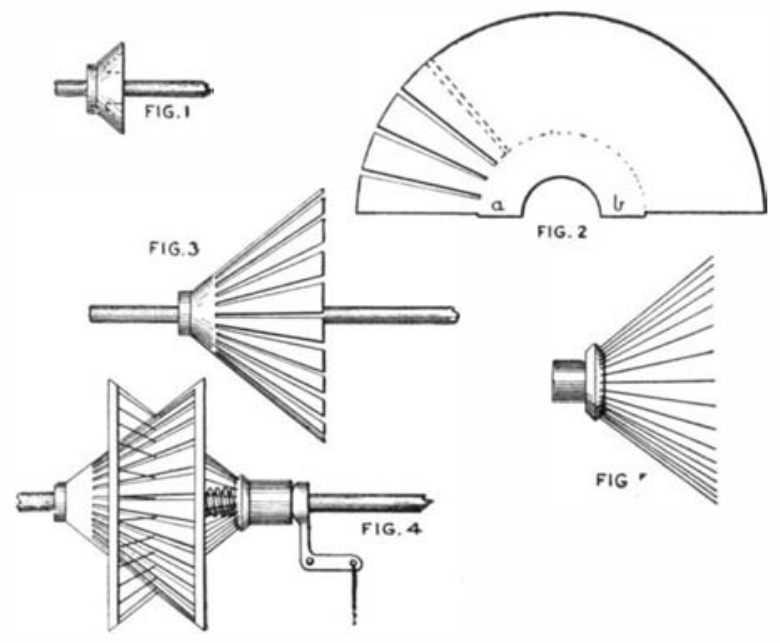

Construction of a variable speed groove-pulley.

Key one of the hubs to the shaft, slip a coil spring in the shaft, bring up the other part, and put them together, as in Fig. 4. To strengthen the pulley a rim can be put on each part. The object of the spring is that when the pulley is wanted larger the spring works the two pulley-members apart and therefore does not injure the belt. Any suitable device may be used to slide them together.

\section{Improvised Forge \\ By Robert K. Patterso}

H AVING an occasion to use a forge where it was H not convenient to carry one along, the writer made very simple one, which would do the work of a factory-made forge, in the following manner: The box of the forge was made of boards. In the bottom of the box a hole two inches in diameter was bored for the air to enter. Then the box was filled in with clay, as shown by the dotted lines in the illustration, to preven the boards from catching fire. The blower was con-

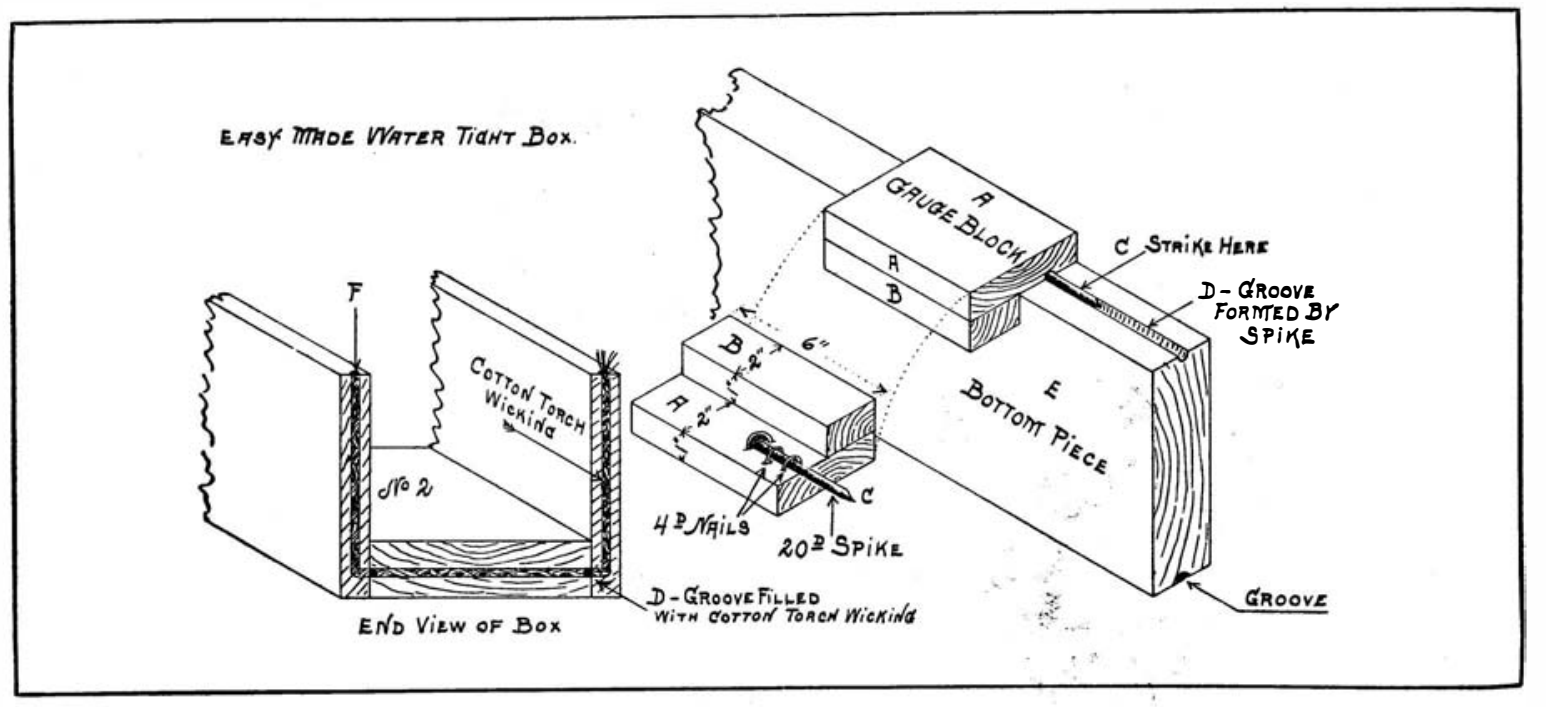

Construction of a water-tight box.

on to the end of the piece. The opposite edge should be similarly treated. In the groove thus formed lay a full strand of cotton torch wicking or oakum twisted to a tight strand that will fill the groove, use the gage block to make the groove across the ends, and fasten the cot- structed by nailing four pieces of $1 / 2$-inch board $51 / 2$ by 5 -inch to a square wooden center. The case consiste of a large lard can, cut so that it was about one incl wider than the fan. There was about $1 / 2$-inch clear ance between the blades of the fan and the case. In the cover and in the bottom of the can a circular hole was cut about 4 inches in diameter for the air to enter, and another hole in the side 2 by 5 inches for the air to escape. The tube leading from the blowe to the box was made of boards having an inside meas

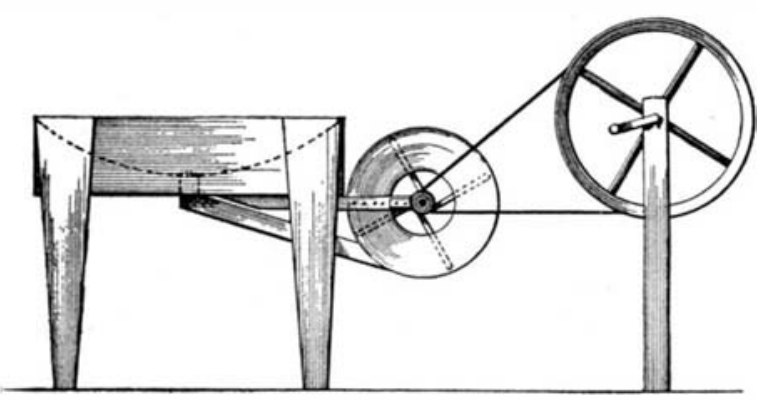

A home-made forge.

urement of 2 inches in height by 5 inches in width at the end attached to the blower. The tube was narrowed (so as to compress the air) until it was only 2 inches wide at the box. At the end of the tube a small hinged door was placed which could be opened so that the ashes, which sifted through the tuyere iron, could be blown out. The tuyere iron in this instance was merely a flat piece of iron drilled full of holes. To drive the blower a large grooved wheel was mounted upon two posts and connected by belt to a pulley on the blower. The latter was fastened upon a large spike by flattening a small nail and driving it in between the pulley and a spot on the spike that had been filed flat so as to form a rude keyway. The sharp end of the spike was flattened as much as possible so that it would not turn after it was driven into the wooden center of the fan. Bolted to the bottom of the box were two strips of hardwood about an inch square and about fourteen inches long. To these the blower was bolted. On the end of the strips a small iron strap was fastened, which had a hole drilled in it to act as a hanger for the fan.

\section{Lineman's Clamp from a Buggy Top} By Elbert S. Ramsay

A Lineman's clamp is a handy but costly tool

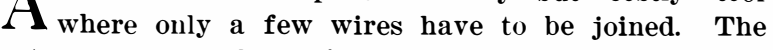
cut shows one the writer has been using for years and finds it answers every purpose. Take an old buggy top prop iron; one with a good strong joint. Put a repair link in the short arm. Cut off the long arm where the link will just slip over the end. Now with a file cut two notches on the inside of each arm, about

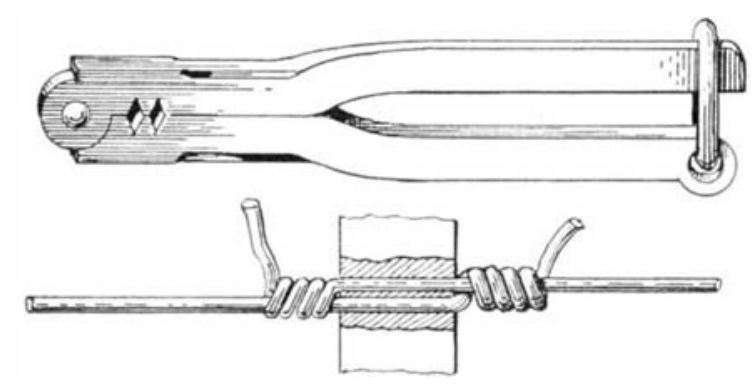

Lineman's clamp made out of a buggy top.

three fourths of an inch from the hinge or joint, taking care that the notches will be in register when the clamp arms are brought together and that the rear notch is just a little larger than the forward one with a very thin wall between them. You can splice a No. 8 wire with ease.

\section{Workshop Notes}

Finest Emery.-Having need of some very fine emery for grinding an engine valve, and having on hand only the ungraded dust from truing up a fine emery wheel, the following operation was resorted to: A handful of the dust was dropped into the emery box from a height of about two feet. After which a sheet of paper was laid on the box and the finest flour of emery settled slowly down upon it. After treating four handfuls in this way more than enough was obtained for grinding the valve. Of course the operation was performed where there was no wind.-JoE V. Romic.

Substitute for a Glass Cutter.-It sometimes happens that when one has to cut glass a glass cutter is not at hand, or the one in use is worn out. The following will make a good substitute. Take an old file, break the end and it will be found that one corner will generally have a very sharp edge, which will cut glass quite as well as any cutter. Of course it soon wears down, but it is merely necessary to break a small piece off the file again and it will be as sharp as before -EMil Vogelin. 